\title{
On the STEM Concept Projection on the Field of Astronomical Knowledge
}

\author{
L.A. Gheonjian *1, 2 \\ $1_{\text {Tamar the King University, Tbilisi, Georgia }}$ \\ ${ }^{2}$ Ivane Javakhishvili Tbilisi State University, Faculty of exact and Natural Sciences, Faculty Institute of Electrical and Electronics \\ Engineering, Tbilisi, Georgia
}

\begin{abstract}
Astronomy, as the result of activity and development of the technology of human cognition of his existence environment, should be considered as the basis for an effective educational approach. The STEM (Science, Technology, Engineering and Mathematics) approach has failed because of limitations caused by the focus on the needs of engineering education only. The STEM projection on the field of astronomical knowledge, technology of means, engineering of instrumentation and mathematical modeling as science and technology language, removes limitations and solves the task to form an educated person. This idea finds solid ground if from philosophy, as a tool for unification, we turn to psychology which studies systems organized around the phenomenon of memory with the goal to reflect and comprehend reality in order to create a new reality and environment for preservation of the viability of human being. This approach is present and developed in different aspects of The General Psychological Theory of Set of Dimitri Uznadze. Based on Uznadze, education is an organized process of accumulation in memory of information that we unconsciously, but adequately use in situations of reality recognizing them as already known. Consciousness serves the memory to create new sets of behavior in new previously unknown situations. Education seems to be ideal, if one step by step organizes situations-tasks of consciousness "switching on" to search for solutions in own memory, in external source or experimentally. If one uses the Psychology of Set as a model of the educational process, astronomy is the best information environment for it.
\end{abstract}

Keywords: Astronomical knowledge, Astronomical Education, STEM concept.

\section{Formulation of the problem}

Astronomy has reached an unprecedented heyday relying on technological progress and setting technological super-tasks of obtaining observational data from the Earth and orbital observatories. We can say that we have come close to creating a model of the universe and are already trying to comprehend the available knowledge for this purpose. Any knowledge, in any field, presupposes bringing information into a certain optimal form suitable both for its storage and for convenient use. As a rule, the task of optimizing the use of information involves the creation of an educational information environment as a springboard for training future professional researchers, but it is equally important to offer this information as a part of the cultural environment taken on trust and stimulating interest in science. In both cases, it is very important to build some information sequences that are easy to understand. However, the construction of each such sequence is not an easy task of adequate information transfer in order to achieve a certain goal.

It would seem that this has long been engaged in education, which has its own specific tools. It also would seem that it is the University that is intended to fulfill this task, and this is its mission. The idea of an ideal university model was introduced in 1944 by Jose Ortega y Gasset (1991). The author found invariants of the model that remain unchanged today. The university is, first and foremost, the higher education that the average person should receive. First of all, the average person should be made a cultural personality, raising him to the level of time. Thus, the first and central function of the university is to familiarize with significant cultural areas of knowledge. The physical image of the World is one of these significant areas. Therefore, when putting in order astronomical knowledge, it is necessary to remember this important goal.

*lev.gheonjian@gmail.com 
The reality that exists around us, created by our civilization, which distinguishes us from the animal and plant world, is created and is created by the development of engineering approaches. Both the "extraction" and "implementation" of our knowledge into reality is largely due to the purposefulness of engineering approaches and a systematic approach developed in this area for identifying problems and solving them (Ackoff \& Emery, 2009). The concept of purposeful systems, brought to an idealized design algorithm (Ackoff et al., 2006), is based on an understanding of the psychology of human activity and is a very effective tool. Moreover, the concept of a purposeful system practically does not differ from the operational definition of intelligence developed in psychology. Apparently the time has come to use the above-mentioned engineering approaches to build a system of astronomical knowledge that is close to the ideal of perception.

This idea finds solid ground if from philosophy, as a tool for unification, we turn to psychology which studies systems organized around the phenomenon of memory with the goal to reflect and comprehend reality in order to create a new reality and environment for preservation of the viability of human being. This approach is present and developed in different aspects of The General Psychological Theory of Set of Dimitri Uznadze (Uznadze (1995), Uznadze (2004)).

\section{Ways to solve the problem}

It is necessary to solve such problems of systematization and ordering of knowledge in a wide variety of areas. We have to admit that the STEM (Science, Technology, Engineering and Mathematics) approach has failed in school and higher education because of limitations caused by the focus on the needs of engineering education only. The engineering approach itself has been misinterpreted. The standardization required for production technology was unsuccessfully projected onto science, mathematics, and engineering itself as a selection of necessary recipes. The creativity of engineering activity turned out to be unaccounted for.

Another thing is the astronomical knowledge at our disposal, which in the very process of its historical development contained a striving for knowledge, supported by the engineering and technology of creating a wide variety of observational means. Mathematics should be considered as a language for modeling objects of observation, and engineering solutions and technology for the implementation of astronomic engineering projects. The entire history of astronomy is a confirmation of this continuously operating approach-algorithm for obtaining knowledge about the world around us.

One of the successful attempts to implement the described approach can be considered a presentation of the evolution of approaches and solutions related to metrology (Hebra (2010)). When reading this book, there is a temptation to build a physics course based on primary metrological standards and to present physics in a new way for engineers and technologists. Other outstanding examples are also known, for example Zeldovich \& Yaglom (1987). Such attempts are always successful when authors consider related fields as tools for obtaining new knowledge in their field.

From the point of view of the cultural value of astronomical knowledge, it would be very useful to build the entire body of astronomical knowledge using the metaphor of our Civilization as the crew of the Spaceship called the Earth, and present astronomers and their activities as the professional activity of navigators and navigators of this ship. The author of this publication consistently and successfully uses this metaphor in public lectures. It is accepted without objection by any audience and listeners of any age. As a rule, one single question-statement arises - is it not so!?

\section{References}

Jose Ortega y Gasset 1991, Mission of the University. Routledge

Ackoff R. L., Emery F., 2009, On purposeful systems: An Interdisciplinary Analysis of Individual and Social Behavior as a System of Purposeful Events. Transaction Publishers, Rutgers - The State University, 35 Berrue Circle, Pisccataway, New Jersey.

Ackoff R. L., Magidson J., Addison H., 2006, Idealized Design: How to Dissolve Tomorrow's Crisis Today . Prentice Hall, Upper Saddle River, New Jersey.

Hebra A., 2010, The Physics of Metrology: All about Instruments - From Trundle Wheels to Atomic Clock . Springer

Uznadze D., 1995, Psychology of Set. Springer

Uznadze D., 2004, General Psychology (in russian). Smisl, Moscow-50, a/b 158.

Zeldovich Y., Yaglom I., 1987, Higher Math for Beginners (Mostly Physicists and Engineers). Mir Publishers 